\title{
Recent Advances in Stem Cell Therapy for Parkinson's Disease
}

\author{
Sidra Asif ${ }^{1}$, Ayesha Hameed ${ }^{1}$, Safia Iswat ${ }^{1}$, Usama Khalid Choudry ${ }^{2 *}$ and Iram Aamir Siddiqa ${ }^{3}$ \\ ${ }^{1}$ Department of medicine, Jinnah Medical and Dental College, Pakistan \\ ${ }^{2}$ Department of General Surgery, Shifa International Hospital, Pakistan
}

${ }^{3}$ Department of physiology, Bahria University Medical and Dental College, Pakistan

*Corresponding author: Usama Khalid Choudry, Department of General Surgery, Shifa International Hospital, Islamabad, Pakistan. To Cite This Article: Usama Khalid Choudry, Recent Advances in Stem Cell Therapy for Parkinson's Disease. 2020 - 7(3). AJBSR.MS.ID.001158. DOI: 10.34297/AJBSR.2020.07.001158.

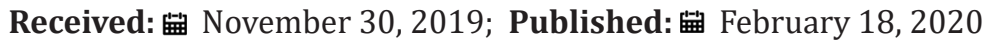

\begin{abstract}
The pathologic hallmark behind Parkinson's disease (PD) is the loss of dopaminergic neurons from the substantia nigra pars compacta (SNpc) and accumulation of lewy bodies (mis-folded proteins). Clinically, in PD the patient encounter with both motor and non-motor symptoms, motor symptoms caused by loss of dopaminergic neurons from the substantia nigra, presented with tremor, bradykinesia and muscle rigidity along with impaired gait, and posture. Recent researches have enlightened the role of different type of stem cell and their clinical application. Stem cell therapy has shown promising effects on the lifestyle and behavioral changes in patients with Parkinson's disease. In this review article we will be discussing about the recent advancements in stem cell therapy for Parkinson's disease.

Keywords: Parkinson's disease (PD); Dopaminergic (DA); Embryonic stem cell (ESCs); Mesenchymal stem cell (MSCs); Neural stem cell (NSCs); Induced pluripotent stem cell (iPSCs)

Abbreviations: PD: Parkinson; SNPC: Substantia Nigra Pars Compacta; PFC: Prefrontal Cortex; LB: Lewy Bodies; SNCA: Alpha Synuclein; P-Tau: phosphorylated Tau; AB: Amyloid Beta protein; SPD: Sporadic PD; MPTP: 1-methyl-4-phenyl-1,2,3,6-tetrahydropyridine; RAAV: Recombinant Adeno Associated Viral Vectors; CRISPR-Cas9: Clustered Regularly Interspaced Short Palindromic Repeats Associated Protein 9; PDD: PD with dementia; LBD: Dementia with Lewy Bodies; P-Tau: Hyperphosphorylation of Tau; NFT: Neurofibrillary Tangles; FTDP: Frontotemporal Dementia with Parkinsonism; MAPT: Microtubule Associated Protein; PARK7: DJ-1; PARK6: PINK1; STN: Sub Thalamic Nuclei; UPS: Ubiquitin Proteasome System; HSP: Heat Shock Proteins; MAO-B: Monoamine Oxidase Type B; BM-MSC: Bone Marrow Derived Mesenchymal Stem Cells; OEC: Olfactory Ensheathing Cells; NSCs: Neural Stem Cells; ESCs: Embryonic Stem Cells; IPSCs: Induced Pluripotent Stem Cells; IDA Neuron: Directly Induced Dopamine Neurons; SVZ: Sub Ventricular Zone; VM: Ventral Mesencephalic; AFG: African Green Monkeys; UPDRS: Unified Parkinson’s Disease Rating Scale; 18F-FDOPA: 18 F-Flurodopa; MSFs: Mouse Embryonic Fibroblast; PSCs: Pluripotent Stem Cells; SHH: Sonic Hedgehog; SCNT: Somatic Cell Nuclear Transfer; CM: Cynomolgus Monkeys; VPA: Valproic Acid; Nr4a2: Nurr1; Ascl1: Mash1; NPCs: Neural Progenitor Cells; A53T: SNCA Mutation; ZFN: Zinc Finger Nuclease; FBS: Fetal Bovine Serum
\end{abstract}

\section{Introduction}

Parkinson's disease (PD) is known to be second most common neurodegenerative disorder after Alzheimer's disease [1] which is becoming a challenge to deal with.

Epidemiological study has revealed that 5 million people after age of 50 years worldwide are affected with PD and it will increase in next 20 years [2]. PD is most common in men (1.5 times) than women [3]. Its incidence is higher in developed countries [4] due to increased age group. Therefore, age is an important risk factor for PD.

Genetic mutations include those in alpha-synuclein (SNCA), Parkin, PINK, DJ-1 (PARK6), Leucine-rich repeat kinase2 (LRRK2), PARK9, GBA (glucocerebrosidase), DNAJC6, SY NJ1, ATXN2, ATXN3, GCH1, DCTN1 etc. [5]. Among these genes SNCA, Parkin, DJ-1, PINK1 are most common gene mutations resulting in PD [6]. People with close relatives with PD do increase their risk of getting PD but still 
the risk is 2-5\% until family has a known mutated gene of PD [7]. Other risk factor is the exposure of the environmental toxins $[4,8]$ such as pesticides, exposure to heavy metals, smoking, interstitial toxins which have shown a marked decrease in dopaminergic neuronal cells $[9,10]$. According to the scientists, PD is not a fatal disease but by time it worsens the normal functions [11].

Treatment of PD with the transplantation of gene is considered to be one of the promising approaches towards the treatment of PD [12]. Over last two years investigators relocated the dopaminergic (DA) cells like adrenal medullary dopaminergic cells, into the striata of PD animal models $[13,14]$. In recent time, researchers manipulated growth factors (FGF-2b, FGF8, SHH) and produced DA neurons from rodent embryonic stem cell and transplanting them into striata of PD animal model. Surprisingly, these transplanted neurons persisted and integrated into normal brain function in PD of animal model $[15,16]$. Researchers can produce yet more DA neurons to transplant into brain of PD animals by overexpression of Nurr 1 in embryonic stem cell [17-20].

Most common tools for reproducing the brain cells include embryonic stem cell (ESCs), mesenchymal stem cell (MSCs), neural stem cell (NSCs) and induced pluripotent stem cell (iPSCs). Several mechanisms like cell replacement, mediating re-myelination, trophic factor and modulation of inflammation can be useful in Stem cell therapies [5].

From years, researches are going on for the treatment and management of PD because it is very common disease in old population in the developed countries. In the past decades, PD was been treated with drugs which has some very severe adverse effects such as wearing off phenomena, motor fluctuation, and abnormal movements as dyskinesia. Beside the drug therapy, surgical treatment is not the option preferred at early stage of disease and it even results in some serious after effects.

The purpose of writing this review article was to highlight the recent approach towards the advancement in the treatment of Parkinson disease with stem cell therapy. We aim to treat PD in future with less symptoms and side effects and to minimize the incidence of PD in future population. Hoping these stem cell therapy will help to reduce the global burden of PD.

Though these new treatments of PD will help in reducing the weightage of PD but much work and new tools are still required for the management and decreasing the graph of PD.

The idea of cell replacement therapy was emerged in 1979, and it was decided to use intra-cerebral grafts of fetal mesencephalic tissue (rich in dopaminergic neuroblasts) in rats [21,22], but clinically it was not implemented because it was not ethically approved to use the tissue from the aborted fetuses and on the other hand even difficult to collect human fetal tissue containing dopaminergic neurons, so it was not performed.
A study done on four patients with PD, by Oslon, Seiger and Backlund $[23,24]$ using autologous graft of adrenal medulla cells into striatum to provide a catecholamine source to the cells, but no good results were produced, so the method was dropped out.

Further in 1987, first intra-striatal implantation of human fetal mesencephalic tissue (taken from 6-9-week old fetus) was performed on patient with PD [25], the aim was to see whether the denerveted striatum could again be reinnervated and transplanted cell could survive, this studies continued until late 1990s. However,this clinical studies was terminated after patients develop dyskinesia [26] and lack of efficacy. Another study was done on patients in Lund, Sweden in the late 1980s to mid-1990s who receive of fetal cell transplantation $[27,28]$ after 15 and 18 years of post-transplantation follow-up the patients motor activity was improved but the non-motor activity didn't show any improvement and graft induced dyskinesia's (GIDs) remains the problem of all the patients [29-31]. The postmortem studies of these patients reveal that the presence of Lewy bodies of about range of $2-8 \%$ and about $80 \%$ of increased levels of alpha synuclein in cell bodies, with premature aging of cell. Furthermore, it suggests that with the time the grafted neuron reduces the dopamine transporter which has its effects on the grafted cells [32-34]. In early 2000s TRANSEURO European Union-funded multicenter started to figure out the stem cell related GIDs and other disorders. They set a protocol to choose patients for transplant, emphasized on young age group with early stage disease.

According to a Commentary published on 2017, Zuo and his colleagues transplanted the human stem cells (hNSCs) on an animal model but instead of focusing on the recovery of nigrostriatal dopaminergic pathway they assess the sub ventricular zone (SVZ), which is a major neurogenic niche(stem cell-enriched brain region).This study leads to underexplored putative regenerative pathway in PD. After testing and imaging, better performance was seen in motor and cognitive task compared to lesion control animal, hence prove the key role of SVZ in recovery. In a nutshell this study suggest that the transplanted stem cell did not directly stimulated the functional activity in PD animals but it promote the activity of neurogenic SVZ through the resident stem cells within the niche, to recruit a complex brain regenerative machinery [35].

\section{Molecular and Genetic Processes in Parkinson's Disease}

Hallmark pathology of Parkinson's disease is loss of dopamine neurons in the substantia nigra pars compacta (SNpc) and diminution of dopamine levels in the striatum [36]. Experiments show that PD has impacts on prefrontal cortex (PFC), anterior cingulate gyrus and/or fronto-striatal pathways as well [37].

Though the exact mechanism of loss of DA neurons in SNpc is not well known. However, the commencement and development of PD may be related to protein misfolding and accumulation, 
over-excitation, oxidative trauma, failure to generate energy, mitochondrial destruction, impairment of pathways of protein clearing, cell-autonomous mechanisms and "prion-like protein infection" [38-40]. The foremost hypothesis for PD amongst them is protein misfolding and its subsequent accumulation in intracellular spaces [41,42]. Lewy bodies (LB) is the chief misfolded amyloid protein in intracellular spaces of SNpc neurons in PD $[38,42,43]$ containing various misfolded amyloid proteins , which includes alpha-synuclein (SNCA), phosphorylated tau (p-tau), and amyloid beta protein $(A \beta)[42,44]$. Sporadic PD (SPD) has various environmental toxins linked to it, and it can be simulated to some extent in experimental PD models of animals, for instance the use of paraquat and 1-methyl-4-phenyl-1,2,3,6-tetrahydropyridine (MPTP) $[45,46]$. In contrast to SPD, familial cases are infrequent, and do not exhibit the symptoms of PD like tremor, bradykinesia and muscle rigidity along with impaired gait, and posture as well as frontostriatal-mediated executive dysfunction, including deficits in attention, speed of mental processing, verbal disturbances, impairment of working memory and impulsivity. This makes it harder in understanding the pathogenesis of PD [41,47].

Limited symptomatic treatments for PD currently existing, are applicable only to a limited amount of patients. Furthermore, permeability issues, short-life span and adverse effects are the chief concerns for the use of these drugs in treating PD. Recent advances in stem cell transplantation [48-50] and gene therapies [51,52] serve as a substitute of drugs in the treatment of PD. For instance, application of genetically engineered DA neurons are proved to be beneficial in PD mouse models [50,53]. Also, improper functioning of metabolic pathways in PD are corrected by scientists by the use of recombinant adeno associated viral vectors ( $\mathrm{AAAV}$ ) or lentiviral [54]. Likewise, current generation of gene editing technique, known as, clustered regularly interspaced short palindromic repeats associated protein 9 (CRISPR-Cas9), have shown to be worthwhile in the treatment of PD [52]

\section{Accumulation of Misfolded Proteins}

\section{Accumulation of alpha-synuclein (SNCA)}

Intracellular accumulation of Lewy bodies in DA neurons of SNpc [55] containing alpha synuclein (SNCA) and other associated proteins is the hallmark pathology in PD [44]. On examining the brains of numerous PD patients, Gomperts and colleagues established a mash of amyloid deposits in their brain, and it was related to cognitive regression without dementia, which proposed that amyloid adds to cognitive, but not motor regression with time [56]. In the same way, Hepp and colleagues proposed that the degree and the level of extension of $A \beta$ pathology adds to congnitive dys-functioning in PD with dementia (PDD) and dementia with Lewy bodies (LBD) [57]. The oligomers, proto-fibrils, and fibrils of SNCA or other misfolded amyloid proteins produce a pore in the membrane and triggering the death of neurons by over-excitation, energy failure, oxidative stress and neuroinflammation $[44,58]$. Likewise, SNCA gene mutations (for e.g. E46K, H50Q, A53T and $\mathrm{A} 30 \mathrm{P})$ are responsible for early beginning, quick progression and greater association of dementia in familial PD [59]. SNCA when overly expressed in animal and cell culture models indicated aggregation of SNCA in mitochondria [60]. Overexpression of SNCA in mice indicated mitochondrial lipid abnormalities and dysfunctioning of electron transport chain [61], and the sensitivity of mice to mitochondrial toxins became less [62]. Studies of human DA neurons in PD brain also showed the presence of respiratory chain dysfunction, oxidative stress and DNA damage in mitochondria [63].

\section{Tau hyper-phosphorylation (p-tau)}

Tau hyper-phosphorylation produce neurofibrillary tangles (NFT), that are paired helical fragments of tau, a characteristic feature of fronto-temporal dementia with parkinsonism (FTDP) [64]. This neurodegenerative disease is related to chromosome 17, with buildup of p-tau in SNpc and cortex [64]. Co-localization of p-tau with LB, often occurs in sporadic PD [65]. Also, mutation in the gene encoding microtubule associated protein (MAPT) produces rise in the levels of p-tau accumulation [65]. The p-tau is also related to mutations in LRRK2 gene [47]. Co-localization of NFTs with SNCA in LB cause disruption in the structure of DA neurons, and this causes quick detoriation and death of DA neurons $[64,66,67]$.

\section{Genetic Mutations in Parkinson's Disease}

Parkin is a protein that plays an important role in ubiquitinproteasome system, which aids in destruction of misfolded proteins. Its mutation results in accumulation of misfolded proteins in SNpc [68]. Mutations of parkin in idiopathic PD patients and in mice that have low levels of parkin, exhibit loss of neurons in locus coeruleus of the midbrain [68]. Parkin also control DA levels that are released by SNpc [36]. DJ-1 (PARK7) is a dimer which is present in the cytoplasm, nucleus, and mitochondria, and PD in early onset is related to this dimer [69]. Its mutation and deletions result in autosomal recessive PD [45]. It also co-localizes with p-tau, SNCA and produces the pathologies of synuclein and p-tau [57]. PINK1 (PARK6) produces a protein called PTEN-induced putative kinase-1, which is located in mitochondria and defend the neurons against stresses that cause mitochondria l injury [70]. Its mutations are seen in PD, where it makes the cells susceptible to damage [70,71]. Its mutations are also related to impairment of mitochondrial functions as well as destruction of SNpc neurons, that results in PD [70].

\section{Excessive Glutamate Production}

Deficiency of DA neurons cause the sub thalamic nuclei (STN) to become over excited, that results in enhanced glutamate production [72]. This then binds to NMDA or AMPA receptors and opens 
calcium channels. Increased levels of calcium cause mitochondrial injury and generate ROS, which cause oxidative injury $[73,74]$.

\section{Alterations Involving Protein Degradation Pathways}

Ubiquitin-proteasome system (UPS): Its dysfunction causes accumulation of amyloid proteins, for instance LB, and intense neurodegeneration in SNpc [75,76]. Molecular chaperones known as heat shock proteins (HSP). HSP70 has an ATPase domain, whose mutation increases the toxicity of SNCA [77]. Likewise, its excess expression in rat brain portions, decreases the toxicity of rotenone or MPTP induced neurotoxicity [78].

\section{Mitochondrial Injury and Oxygen Trauma}

ATP production in the cells is affected due to impaired activity of complex-I in mitochondria, which results in cellular death [79]. Brain monoamines, including DA and 5-HT serve as antioxidants [80]. DA degradation by monoamine oxidase type B (MAO-B), along with the available ground state oxygen, results in ROS production [81]. In PD, there is a rise in oxidative stress markers along with related changes (e.g damage to DNA, proteins and fats by free radicals) [81].

\section{Prion Hypothesis}

In this hypothesis, it is proposed that SNCA, analogous with prion proteins, extends throughout the CNS, and contaminate nearby novel and fit neurons, and it goes on until most of the damage has occurred. Thus, this type of infection may be the cause of development and neuronal degeneration in certain sorts of PD [42].

PD leads to temperamental, social and economical disintegration to patient's relatives, friends and family. Unluckily, efficacious remedies are not presently achievable, despite of that, rapid detection and suitable mitigative therapies can offer a much effective and prolonged life span for the patients of PD.

\section{Sources of Stem Cells}

Bone-marrow derived mesenchymal stem cells (BM-MSC) and olfactory ensheathing cells (OEC) have been used for the treatment of PD, but these have less potential in differentiating to DA neurons [82-84]. Presently, researchers are working on carrying out studies on different cell lines which include neural stem cells (NSCs) and human fetal dopamine (DA) neurons, embryonic stem cells (ESCs), induced pluripotent stem cells (iPSCs) and directly induced dopamine neurons (iDA neuron) generated from autologous somatic cells [85-87].

\section{Recent Advancements in Different Stem Cell Sources}

\section{Neural stem cells (NSCs) and human fetal DA neurons}

In 1965, Neural stem cells (NSCs) were documented at first [88] and were characterized as granule cells having greater degree of proliferation in brain cortices. They can be transformed into astrocytes, oligodendrocytes and neurons. NSCs can be obtained from hippocampus, sub ventricular zone (SVZ) of brains of adult mammals and other areas of fetal brains as well $[89,90]$. When NSCs obtained from mouse and humans are implanted into brains of rats, they locate and relocate and transform in a pattern that is confined to a particular locus. In PD rats that have low DA proportion, NSCs favorably transform into DA neurons [91]. Transcription proteins such as Lmx1a and Msx1 were manifested in DA neural progenitor in ventral part of midbrain and these proteins induce DA neuron production with midbrain similarity. They caused the differentiation of neural progenitor cells into DA neurons in midbrain of chick embryos and are responsible for their selectivity and development. NSCs were transformed into DA neurons by five-step procedure. By overexpression of ASCL1 which is a transcription factor, human neural progenitor cells generated larger neurons which had much more neuritis [92]. NURR1 is a regulatory protein in DA neuron differentiation, growth and proliferation of DA neurons [93]. Its overexpression caused NSCs of mouse models to transform into DA neurons and persist in vivo in PD rats [94].

There are a few studies which suggested little recovery after grafting substantia nigra-derived fetal cells into PD models of rats, but most found most favorable results $[95,96]$. Redmond et al. [97] demonstrated ventral mesencephalic (VM) neurons tissue when grafted to the 1-methyl-4-phenyl-1,2,3,6-tetrahydropyridine (MPTP)-lesioned African Green Monkeys (AFG) persisted in their brains and all the animals became better in behavioral aspects by 9 months of post-transplantation in primate model of PD [97].

First clinical trials occurred in Sweden in 1980's in animal research studies to graft fetal DA neurons to patients of PD in placebo-controlled trials [98]. Motor functions were measured quantitatively, and clinical trials were carried out to implant human fetal DA neurons to patients of PD. Noteworthy effects were observed in behavioral and histological aspects in these researches [99,100] Freed et al. conducted double-blind, sham surgery-controlled study by nominating 40 patients with average PD span of about 14 years and haphazardly distributing them into two groups each having 20 patients. The transplantation group received fetal neural cells bilaterally while the control group received sham surgery. They all were assessed one-year posttransplantation which was done on Unified Parkinson's Disease Rating Scale (UPDRS). In comparison to control group, noteworthy therapeutic effects were observed in patients at 60 years of age and younger and showed no noteworthy therapeutic effects in adults, with variations in therapeutic effectiveness. Olanow et al. [101] conducted double-blind control trial with 34 patients of severe PD for two years post transplantation. They were haphazardly given bilateral grafting of fetal DA neurons as transplantation group or sham surgery as control group. At postmortem examination, robust DA neurons persisted yet no noteworthy improvements were 
observed in transplantation versus control group [101]. Additional double-blind study was conducted in which 33 patients grafted with fetal DA neurons were followed up for two years and out of these, 15 patients were followed up for 2 years or further. On UPDRS motor ratings, noteworthy therapeutic benefits were observed the uptake of [48] F-flurodopa (18F-FDOPA) by putamen was observed. PET showed that fetal grafts survived in patients of PD over the study of four years [102]. Though, dyskinesia was observed as a consequence of such grafts, predominantly seen in those taking levodopa for PD. [101] Olanow et al. identified that about $56 \%$ of PD patients suffered from sustained dyskinesia after the removal of medication they were taking for $\mathrm{PD}[101]$ which was quiet much than $15 \%$ of PD patients who developed dyskinesia Freed et al. [100] reported. After transplantation of such neural grafts, relapse of dyskinesia has been reported [103,104]. Contexts have proved that these grafts contain serotonin neurons that are related to such dyskinesia, therefore, cells with homogenous populations should be used for grafting $[105,106]$.

A study was conducted, which showed that grafted fetal DA neurons persisted for about 14 year without producing any detrimental effects, indicating their invulnerability and usefulness [107]. Two studies were performed and showed that Lewy bodies containing alpha-synuclein disseminated to the grafted DA neurons 14 or16-years post-transplantation [108,109] suggesting that it can be a continuous process.

A multicenter and collaborative study of European Union (TRANSEURO) was established in 2010, which formed new strategies for clinical trials of fetal midbrain DA therapy for patients of PD. These comprise of mindful selection of patients, who are of 30 to 68 years at inclusion time period, responding well to levodopa, are at early stages in their disease process, site of graft implants should be assesses systematically, standards of clinical analysis, amount of patients and post-transplantation immunosuppression and time of follow-up. TRANSEURO performed new clinical trials of greater than 100 patients of $\mathrm{PD}$ and results are in the process of analysis $[110,111]$.

\section{Human Embryonic Stem Cells (HESCs)}

Embryonic stem cells (ESCs) are pluripotent and self-restoring cells that are segregated from inner cell mass of the pre-implantation blastocysts [112]. They can differentiate into any sort of tissue, for instance DA neurons, neural stem cells (NSCs) and neurons, hESCs were first segregated by their inner cell mass cells culture with feeder cells that are obtained from mouse embryonic fibroblast (MSFs) [113,114]. Yan et al. established strategies to produce midbrain-like DA neurons from hESCs that are obtained from neuroepithelial cells by adding growth factor SHH and FGF8 in a definite pattern [114]. Initial precursors assume a region peculiarity which caused transformation of midbrain neuroepithelial cells. Locomotive defects in rat models of PD showed betterment after the application of hESC-derived DA neurons, as long as these started to function in vivo $[115,116]$. Chamber et al. established a strategy to improve the effectiveness of DA production from pluripotent stem cells (PSCs). They proposed that propagation and persistence of DA neurons from hESCs is increased by inhibiting SMAD signaling [116]. Noggin and SB431542, when added to prevent SMAD signaling, causes neural transformation of $>80 \%$ of hESCs which was carried out in adherent culture environment Fasano et al. [117] proposed that those neurons which show failure to develop towards anterior regionalization, can be transformed to midbrain DA neurons by the addition of FGF8 or Wnt1 [117]. They also established a floor plate-based technique to produce DA neurons from hESCs in a differentiation medium, which contains activators of sonic hedgehog (SHH) and WNT signaling in vitro. DA neurons thus obtained, propagated for greater than 18 weeks and also restored the rotation dysfunctions caused by amphetamine in vivo after their grafting into 6-OHDA_lesioned rats and MPTPlesioned rhesus monkeys [118]. Another group study, revealed that by the use of lentiviral vectors in hESCs for the expression of a gene LMX1A, that regulates DA neurons, generated A9 subtype of ventral midbrain DA neurons for greater than $60 \%$ of all neurons being produced by LMX1A-tranfected hESCs [119]. Major problems regarding stromal cells use as feeder cells for culture of cells derived from hESCs are that these have few rodent cells in them which have associated risks of immune rejections. To solve this issue, few studies established feeder-free culture system that utilize matrigels in place of feeder cells $[92,93]$ Schulz et al. [120] produced DA neurons in serum-free suspension approach [120] Vazin et al. [121] substituted PA6 stromal cells with growth factors IGF2, SDF1, EFNB1, and PTN. These factors caused the transformation of hESCs into TH-positive DA neurons directly [121]. After the early differentiation step of hESCs into NSCs, growth factors SHH and FGF8 were shown to substitute for PA6 stromal cells. Serum was not included in their culture strategies. A significant innovation made by them was that cells could be reinstituted at each of the intermediate stages in their four-stage process (ESC proliferation $\rightarrow$ NSC production $\rightarrow$ DA neuron precursor induction $\rightarrow$ DA development) destitute of function deprivation, causing the cells to be grafted at a relevant point in developing neurons [122]. Clinical trials are not still conducted for treating patients of PD, though hESCs can be transformed into many DA neurons in vitro and have also proved to reinstitute motor disorders in animal models of PD. Matter of concerns are: 1) the stability in physical composition of DA neurons post-transplantation, and 2) concerns regarding hESCs that remain undifferentiated that have the potential for tumor development. Moreover, there are ethical concerns as well.

\section{Induced pluripotent stem cells (iPSCs)}

Preliminary studies proved that somatic cell nuclear transfer (SCNT) is used to reprogrammed differentiated somatic cells into an undifferentiated form [123-125]. However, this technique has 
not yet applied to generate patient specific cells [126,127]. Mouse iPSCs were produced first in Yamanaka lab in 2006 by the lentiviral expression of four transcription factors: Sox2, c-Myc, Oct3/4, and Klf4 in fibroblasts obtained from mouse embryos [128]. Shortly, Yamanaka lab and other labs, utilized human orthologs of these four transcription factors: Sox2, NANOG, OCT4, and LIN28, for the production of human iPSCs as well for those patients who were related to diseases like PD [128-130]. Oct3/4 and Sox2 play an important part in the proliferation of undifferentiated ESCs in culture [131]. Klf4 and c-Myc aid in somatic cells reprogramming . Subsequent studies proved that Oct3/4 and Sox 2 seem to be the only genes necessary for the production of iPSCs [132] while Klf4 and c-Myc are not of use [133]. Reprogramming of differentiated somatic cells of an organism to pluripotent embryonic-like form produces iPSCs. They possess less risks of rejection since the cultured cells are autologous. However, ethical concerns are still a problem. As soon as they are reprogrammed into iPSC form, growth factors are introduced into them so as to differentiate them into specific lineages (eg: NSCs or DA neurons) [134,135]. Effects of therapy with mouse iPSCs were studied by grafting them into brain of rats [136]. It was reported that transplanted iPSCs developed into DA neurons. This resulted in betterment of behavioral symptoms in PD models of rats. Further studies reported that, neural stem cell or iPSCs obtained from humans proved to be effective in PD models of rat and monkey [137-140]. Regarding the utilization of iPSCs for treating PD, no clinical trials have yet been performed. Since the interaction between transgenes and viral vectors in the iPSC genome may result in malignant mutations or may derange their differentiation capability, Jaenish et al. generated such iPSCs for PD patients which lack transgenes. This was done by an enzyme called "Cre recombinase", which removes the reprogramming factors. This type of patient-iPSCs presented global gene expression which seem to be similar to hiPSCs and hESCs that bear transgenes [141]. The degeneration of DA neurons was fixed by the repairing the LRRK2 G2019S mutation, which shows that this mutation is an essential factor in causing PD [142] Isacson et al. [97] utilized stromal feeder cell-based strategy and grafted DA neurons differentiated from non-viral PD-iPSCs into rat models which have 6-OHDA lesions. It was reported that these neurons persisted and showed functional recovery by decreasing the rotational asymmetry caused by apomorphine [138]. This group also reported that autologous iPSCs obtained from cynomolgus monkeys (CM) when autologous grafted into CM having MPTP lesions, proved to have long-standing improvements in functions and persisted for about 2 years and also the brain of CM was re-innervated [143]. Transplantation of iPSCs-NSCs recovered the motor deficits of rat models with PD from 4th-16th week [137]. Reprogramming efficacy became better by using histone deacetylase, valproic acid (VPA) and DNA methyltransferase inhibitors, especially increasing th efficacy by two orders of magnitude, about 10\%, in the absence of c-Myc Stadtfeld et al. [144] reprogrammed liver cells of mouse into iPSCs by the expression of four transcription factors of adenoviruses [144] Okita et al. [145] generated iPSCs by putting plasmids containing the suitable genes repeatedly into fibroblasts of embryo [145]. By the use of the transposon piggyback, this strategy was utilized in human cells by Kaji et al. [146] which carried the chances of remaining sequences and chromosomal mishaps. iPSCs lacking transgene sequences and vector are also produced by utilizing non unified episomal vectors [147]. Direct protein transduction system which lacks DNA vector generates iPSCs that have no chances of integrations and mutations in chromosomes [97] Isacson et al. [148] proposed a proficient method for differentiation and sorting of DA neurons from human ES as well as human iPS cells. VMDA neurons augmented with NCAM (+) / CD29 (low), were sorted out from pluripotent stem cell-differentiated cells. These sorted neurons were positive for EN1/TH and FOXA2/TH and expression of NURR1, EN1, GIRK2, PITX3, TH, FOXA2, and LMX1A was very high, clearly showing that the neural cells that were sorted out are DA neurons. This proved that cell therapies obtained from iPSCs are quite secure and useful techniques for future therapies [139]. Certain amendments are made to decrease the mutagenicity of utilized lent viruses and retroviruses. For instance, c-Myc retrovirus when gets reactivated, may possess tumor potential [149]. Though, c-Myc removal may result in decreased efficacy in iPSC generation. Replacement of Klf4 and c-Myc with Nanog and Lin28, decreases the chances of tumor formation to a greater extent. This proves that c-Myc is responsible for propagation or increasing the rapidity of phases that develop pluripotency, whereas developing pluripotency by itself is not compulsory [121] Chen et al. [150]. established a suspension system for culturing, and it was habituated by O'Brien [151] and Laslett [152] to utilize them in hESCs and hiPSCs (revised by Serra et al. [153]. Long duration of culturing is maintained in such systems, yet preserving the usual karyotype, pluripotency, and expropriate expression of markers. A factor OCT4 along with CHIR 99021, TGF- $\beta$ inhibitor, and VPA can derive iPSCs from adult and mouse fibroblasts [133]. Currently, a study proved that iPSCs of rhesus monkey naïve are obtained simply with smaller molecules, escaping OCT4, serving to be an important cell source to be utilized therapeutically as well as in researches [154].

\section{Directly Induced Dopamine Neurons (iDA neurons)}

Complex ways in the production of iPSCs, representation, differentiation, and description into DA neurons have made the researchers to sort out achievable and obtainable ways to generate DA neurons. Similarly, the undifferentiated cells present in iPS cell population can result in development of tumor and restrict their utilization clinically. Currently, it has been reported that by incorporating different sort of mixtures of the transcription factors Nurr1 (Nr4a2), Mash1 (Ascl1), Ngn2, Sox2, Lmx1a, and Pitx3 and reprogramming them with fibroblast result in DA neurons production [155-157]. Caiazoo et al. proposed that DA neurons can 
be reprogrammed directly from human and mouse fibroblasts by the action of three transcription factors, Nurr1 (Nr4a2), Lmx1a, and Mash1 (Ascl1). These directly reprogrammed DA neurons have similar activity as DA neurons [155] Kim et al. [157] proposed that DA neurons that are similar to midbrain DA neurons express the neuron marker Pitx3 and are generated by the lentiviral expression of eight transcription factors EN1, Nurr1, Lmx1a, Mytl1, Acsl1, Brn2, Lmx1b, Pitx3. To generate DA neurons from fibroblast, two of these transcription factors are important, and these include Pitx3 and Acsl1. The directly converted DA neuron thus formed appear to function in PD mouse models [158]. The transcription factors that were responsible for generating neural progenitor cells (NPCs) from fibroblasts were amalgamated along with culture medium having SHH and FGF8 in it, by Kim et al. [158] As a result, DA neurons releasing dopamine and expressing TH were generated successfully [157].

There are certain issues regarding to whether directly reprogrammed DA neurons are harmless and risk free for utilization in clinics or not. Anyhow, proceeding approaches in the studies will ultimately surpass these concerns and put forward these neurons to clinical experiments and trials for PD.

\section{An Outlook on Future of Stem Cell Therapy For PD}

Immune rejections and ethical concerns are the major issues regarding the use of hESCs, NSCs and DA neurons obtained from fetal brain. However, autologous cell therapy for PD served the purpose of generating iPSCs and iDA neurons. Still, there are a number of concerns regarding the utilization of iPSCs for clinical purposes which need to be sorted out, including genetic and epigenetic aberrations, limited production, and degree of safety of iPSCs-derived cells.

\section{Limited production}

Fully reprogrammed cells have less productivity. But this will continue to become better and it is expected that its production will increase in future. VPA and additional chemicals have enhanced the production by $0.05 \%[159,128]$ Yamanaka et al. established a random model, in which he proposed that almost all or many of the differentiated cells possess the ability to be transformed into iPSCs. Nevertheless, they are generated from fibroblast cells, yet they are also generated from a wide range of cells of the three types of cell lines, which include endodermal, mesodermal and ectodermal cells. Stadtfeld et al [101,144] utilized cells of liver; Aoi et al. [160] utilized cells from liver and stomach; Aasen et al. [161] utilized cells obtained from adult human hairs. This shows cells can be obtained from any part of adult human and have different productivities through experiments. Aasen et al. [161] proposed that iPSCs generated from keratinocytes, obtained from adult human hairs, were not indistinct from ESCs and were 100 times more efficacious in comparision to reprogramming of human fibroblasts [161].
Future should focus on the aims to increase the production of iPSCs and also to focus more on identifying the efficacious methods of generation of iPSCs.

\section{Genetic and Epigenetic Abberations}

Epigenetic memory in iPSCs and iDA neurons on cell fates are noteworthy issues. They are linked to their originators or else sustaining marks of reprogramming after differentiation $[162,163]$. Reprogramming techniques done by using reteroviruses or lentiviruses should be substitutes by vectors which are nonintegrating, in order to associate with smaller molecules or else for the expression of reprogramming genes, for the production of iPS cells that are clinically useful [164]. There are a few PD patients-derived iPSCs which has a number of gene mutations in it, chromosomal structure mutations, point mutations, gene duplications, and SNCA genes deletion, Parkin, LRRK2, GBA or more [142,165-169]. It was proposed that iPSCs having SNCA mutation (A53T) can be corrected by zinc-finger nuclease (ZFN)-mediated nuclease method and genetic repair of the A53T mutation in iPSCs from PD patients did not influence the property to transform into DA neurons. Properly rectified iPSC lines from PD patients were confirmed by sequencing analysis and PCR genotyping. LRRK2 G2019S mutation were repaired and this resulted in phenotypic release in transformed cells [142].

\section{Degree of Harmlessness and Stem Cell Purity}

In order to generate DA neurons or NSCs from iPSCs for the management of $\mathrm{PD}$, it is important that the population of untransformed or undifferentiated cells are lower than $1 \%$ in order to be protected against tumor development post-transplantation. FACS and other non-invasive magnetic selection are the sorting out techniques generated for the cells obtained from iPSCs. Furthermore, culture medium of cells should be without feeder cells to escape animal contagion. Presently, feeder cells obtained from murine sources are utilized to retain hiPSCs and hESCs. Additionally, culture environment which has fetal bovine serum (FBS) in it, is generally utilized for culturing the feeder cells. It will result in allogenic cell contagion of cells generated from iPSC. A current study generated a system free of feeder cells for culturing the iPSCs and hESCs in the StemFit ${ }^{\mathrm{TM}}$ medium, making a huge initiative for the production of GMP-standard cells feasible for clinical use [170].

\section{Is stem cell therapy a better control of symptoms or a cure?}

There are many articles and researches enlightening the advantages of stem cell therapy and promises a better cure of PD. The aim of stem cell therapy is not only to restore the lost dopaminergic neurons but also to halt the disease progression. The best achievement that can ever be achieved is the repair of striatal dopaminergic innervation to the normal range. Fetal mid brain 
allograft has shown some improvement in patients lifestyle and functional activity but still, it is not providing a cure [171]. Even if the dopamine neurotransmitters are restored, it will again be a question whether it will be effective in every advanced PD. We have given a proposed model regarding our findings in Figure 1 as a summary.

\section{Conclusion}

The occurrence of PD is increasing day by day, because of the growing population of elderly. Its commercial and psychological influences on the wellbeing of population as well as on those close relatives and friends of the patients afflicted with PD seem to be profound. Several treatments are available but none of them have proved to be beneficial in decreasing the loss of DA neurons or in reestablishing the normal levels of DA in striatum. There are however a number of drugs for treating PD, but these are either costly or have dangerous adverse effects. Currently, researches have proposed propitious methods in place of drug therapies, including stem cell grafting and gene therapy for PD and other neurodegenerative therapies. Studies are performed on the use of all cell sources derived - fetal NSCs, ESCs, iPSCs and iDA neurons in different animal and human models. NSCs transformed into DA neurons in PD rat models as well as in placebo-controlled trials, double-blind studies and clinical trials have proved to produce noteworthy therapeutic effects. However, graft induced dyskinesia were observed which were probably due the presence of serotonin neurons among NSC population can be prevented by using homogenous population of cells. Regarding hESCs, Clinical trials have not been performed yet for the treatment of PD, though in vitro studies have shown that they transformed into DA neurons and improved motor deficits in animal models. Matter of concerns however, are:

i. the stability in physical composition of DA neurons posttransplantation, and

ii. concerns regarding hESCs that remain undifferentiated that have the potential for tumor development.

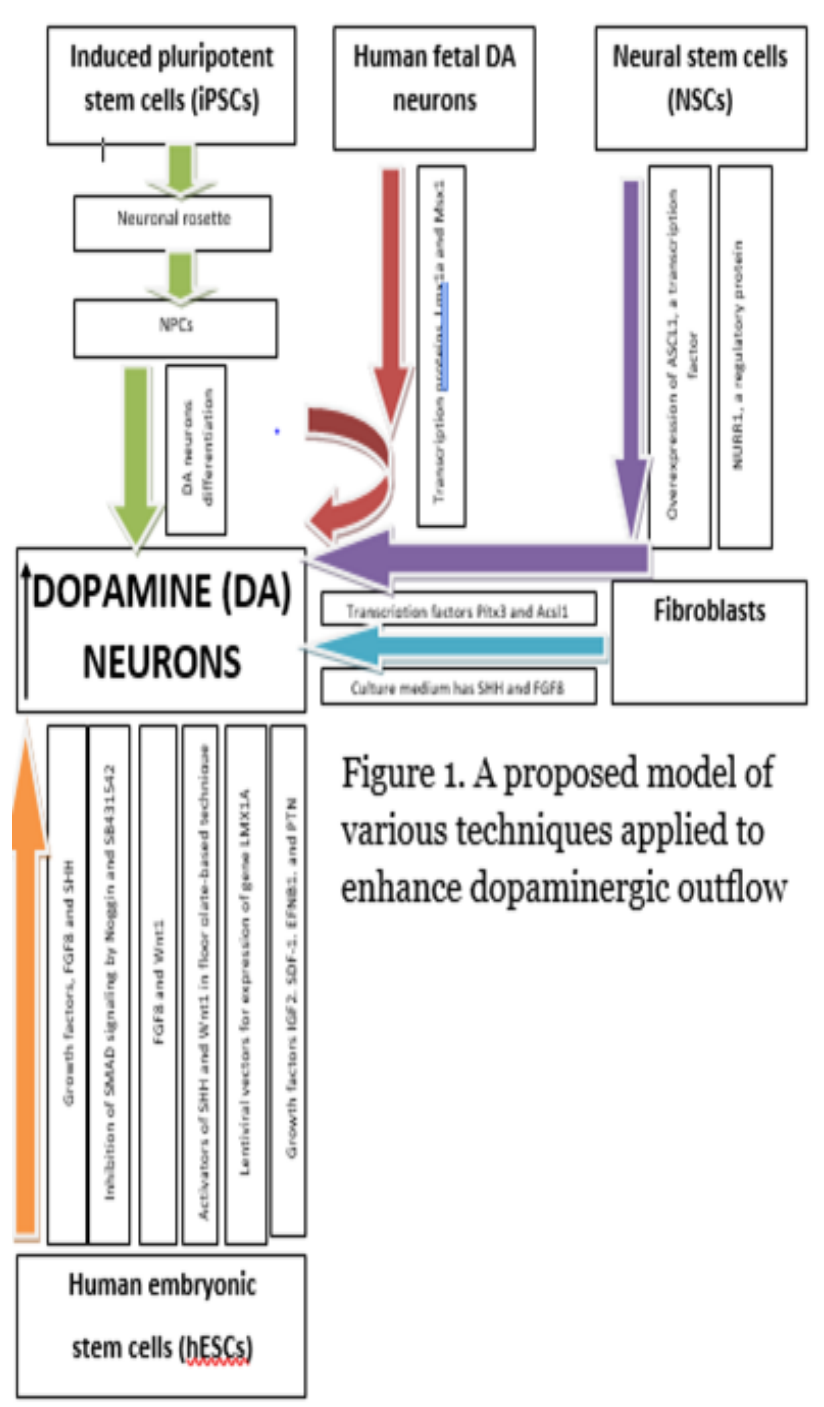

Figure 1: A proposed model of various techniques applied to enhance dopaminergic outflow 
Moreover, there are ethical concerns as well. Researchers are on the way to great success in the generation iPSC derived cells for treating PD. Though, no clinical trials have yet been performed for PD, but they have proved therapeutically effective in animal models. There are, however, restrictions and drawbacks associated with iPSCs. Ethical concerns are also a problem. To understand their entity and survival rates for treating PD, pre-clinical studies might also be needed. Unless further studied and the degree of their efficiency and harmlessness is established, iPSCs should not be brought to clinical trials. Undifferentiated cells in iPSCs have risks of tumor production, therefore, researchers are working in carrying out direct production of DA neurons. Successful approaches are made which show that directly induced DA neurons (iDA) can be obtained from mouse and human fibroblasts by adding transcription factors into them. Among the transcription factors, two of them play an important role and these include Pitx3 and Ascl1.Currently, researchers are working on most of these recent stem cell therapies, with majority being performed only on animal models, thus, degree of harmlessness and efficiency must be satisfactorily determined and ethical issues must also be resolved. Nevertheless, recent therapies and their advancements described in this review provide us with hopes that efficient treatments for PD will soon be established (Figure 1).

\section{Ethical Statement}

1. Funding: (if any): self

2. Conflict of Interest: Nil

3. Ethical approval: Not required

4. Informed consent: Not required

\section{References}

1. Wirdefeldt K, Adami HO, Cole P, Trichopoulos D, Mandel J (2011) Epidemiology and etiology of Parkinson's disease: a review of the evidence. Eur J Epidemiol (Suppl 1): S1-S58.

2. Dorsey ER, Constantinescu R, Thompson JP, Biglan KM, Holloway RG, et al. (2007) Projected number of people with Parkinson disease in the most populous nations, 2005 through 2030. Neurology 68(5): 384386.

3. Davie CA (2008) A review of Parkinson's disease. Br Med Bull 86: 109127.

4. Bove J, Prou D, Perier C, Przedborski S (2005) Toxin-induced models of Parkinson's disease. NeuroRx 2(3): 484-494.

5. Prasad YH, Yun L (2015) The Development of Treatment for Parkinson's disease. Advances in Parkinson's Disease 4: 59-78.

6. Klein C, Westenberger A (2012) Genetics of Parkinson's disease. Cold Spring Harb Perspect Med 2(1): a008888.

7. Goldenberg MM (2008) Medical management of Parkinson's disease. P \& T 33(10): 590-606.

8. Cannon JR, Greenamyre JT (2011) The role of environmental exposures in neurodegeneration and neurodegenerative diseases. Toxicol Sci 124(2): 225-250.
9. Hatano T, Hattori N (2011) Aetiology and Pathogenesis of Parkinson's Disease, Aetiology and Pathophysiology of Parkinson's Disease. Abdul Qayyum Rana (Ed).

10. Corti O, Lesage S, Brice A (2011) What genetics tells us about the causes and mechanisms of Parkinson's Disease. Physiol Rev 91(4): 1161-1218.

11. Ishihara LS, Cheesbrough A, Brayne C, Schrag A (2007) Estimated life expectancy of Parkinson's patients compared with the UK population. J Neurol Neurosurg Psychiatry 78(12): 1304-1309.

12. Goodarzi P, Aghayan HR, Larijani B, Soleimani M, Dehpour AR, et al. (2015) Stem cell-based approach for the treatment of Parkinson's disease. Med J Islam Repub Iran 29: 168.

13. Solari N, Bonito Oliva A, Fisone G, Brambilla R (2013) Understanding cognitive deficits in Parkinson's disease: lessons from preclinical animal models. Learn Mem 20(10): 592-600.

14. Dauer W, Przedborski S (2003) Parkinson's disease: mechanisms and models. Neuron 39(6): 889-909.

15. Kim JH, Auerbach JM, Rodriguez Gomez JA, Velasco I, Gavin D, et al. (2002) Dopamine neurons derived from embryonic stem cells function in an animal model of Parkinson's disease. Nature 418(6893): 50-56.

16. Kim HJ (2011) Stem cell potential in Parkinson's disease and molecular factors for the generation of dopamine neurons. Biochim Biophys Acta 1812(1): 1-11.

17. Roybon L, Christophersen NS, Brundin P, Li JY (2004) Stem cell therapy for Parkinson's disease: where do we stand? Cell Tissue Res 318(1): 261-273.

18. Zhang SC, Li XJ, Johnson MA, Pankratz MT (2008) Human embryonic stem cells for brain repair? Philos Trans R Soc Lond B Biol Sci 363(1489): 87-99.

19. Oh SM, Chang MY, Song JJ, Rhee YH, Joe EH, et al. (2015) Combined Nurr1 and Foxa2 roles in the therapy of Parkinson's disease. EMBO Mol Med 7(5): 510-525.

20. Fu MH, Li CL, Lin HL, Chen PC, Calkins MJ, et al. (2015) Stem cell transplantation therapy in Parkinson's disease. SpringerPlus 4:597.

21. Perlow MJ, Freed WJ, Hoffer BJ, Seiger A, Olson L, et al. (1979) Brain grafts reduce motor abnormalities produced by destruction of nigrostriatal dopamine system. Science 204(4393): 643-647.

22. Bjorklund A, Stenevi U (1979) Reconstruction of the nigrostriatal dopamine pathway by intracerebral nigral transplants. Brain Res 177(3): 555-560.

23. Backlund EO, Granberg PO, Hamberger B Knutsson E, Mårtensson A, et al. (1985) Transplantation of adrenal medullary tissue to striatum in parkinsonism. First clinical trials. J Neurosurg 62(2): 169-173.

24. Lindvall O, Backlund EO, Farde L, Sedvall G, Freedman, et al. (1987) Transplantation in Parkinson's disease: two cases of adrenal medullary grafts to the putamen. Ann Neurol 22(4): 457-68.

25. Lindvall 0 (2016) Clinical translation of stem cell transplantation in Parkinson's disease. J Intern Med 279(1): 30-40.

26. Olanow CW, Goetz CG, Kordower JH, Stoessl AJ, Sossi V, et al. (2003) A double-blind controlled trial of bilateral fetal nigral transplantation in Parkinson's disease. Ann Neurol 54(3): 403-414.

27. Hagell P, Schrag A, Piccini P, Jahanshahi M, Brown R, et al. (1999) Sequential bilateral transplantation in Parkinson's disease: effects of the second graft. Brain 122(pt 6): 1121-1132.

28. Brundin P, Pogarell O, Hagell P, Piccini P, Widner H, et al. (2000) Bilateral caudate and putamen grafts of embryonic mesencephalic tissue treated with lazaroids in Parkinson's disease. Brain 123(pt 7): 1380-1390. 
29. Politis M, Wu K, Loane C, Quinn NP, Brooks DJ, et al. (2010) Serotonergic neurons mediate dyskinesia side effects in Parkinson's patients with neural transplants. Sci Transl Med 2(38): 38ra46.

30. Hagell P, Piccini P, Björklund A, Brundin P, Rehncrona S, et al. (2002) Dyskinesias following neural transplantation in Parkinson's disease. Nat Neurosci 5(7): 627-628.

31. Politis M, Oertel WH, Wu K, Quinn NP, Pogarell O, et al. (2011) Graftinduced dyskinesias in Parkinson's disease: high striatal serotonin/ dopamine transporter ratio. Mov Disord 26(11): 1997-2003.

32. Li JY, Englund E, Holton JL, Soulet D, Hagell P, et al. (2008) Lewy bodies in grafted neurons in subjects with Parkinson's disease suggest hostto-graft disease propagation. Nat Med 14(5): 501-503.

33. Kordower JH, Chu Y, Hauser RA, Freeman TB, Olanow CW (2008) Lewy body-like pathology in long-term embryonic nigral transplants in Parkinson's disease. Nat Med 14(5): 504-506.

34. Brundin P, Kordower JH (2012) Neuropathology in transplants in Parkinson's disease: implications for disease pathogenesis and the future of cell therapy. Prog Brain Res 200: 221-241.

35. K Heese (2017) Restorative Neurology and Neuroscience.

36. Dauer W, Przedborski S (2003) Parkinson's disease: mechanisms and models. Neuron 39(6): 889-909.

37. Shepherd GM (2013) Corticostriatal connectivity and its role in disease. Nature Reviews Neuroscience 14(4): 278-291.

38. Alexander GE (2004) Biology of Parkinson's disease: pathogenesis and pathophysiology of a multisystem neurodegenerative disorder. Dialogues in clinical neuroscience 6(3): 259-280.

39. Davie CA (2008) A review of Parkinson's disease. Br Med Bull 86: 109 127.

40. Michel PP, Hirsch EC, Hunot S (2016) Understanding dopaminergic cell death pathways in Parkinson disease. Neuron 90(4): 675-691.

41. Martin I, Dawson VL, Dawson TM (2011) Recent advances in the genetics of Parkinson's disease. Annual review of genomics and human genetics. 12: 301-325.

42. Chauhan A, Jeans AF (2015) Is Parkinson's disease truly a prionlike disorder? An appraisal of current evidence. Neurology research international 2015: 345285 .

43. Berg D (2008) Biomarkers for the early detection of Parkinson's and Alzheimer's disease. Neurodegenerative diseases 5(3-4): 133-136.

44. Kim WS, Kågedal K, Halliday GM (2014) Alpha-synuclein biology in Lewy body diseases. Alzheimer's research therapy 6(5): 73.

45. Bové J, Prou D, Perier C, Przedborski S (2005) Toxin-induced models of Parkinson's disease. NeuroRx 2(3): 484-494.

46. Bus JS, Gibson JE (1984) Paraquat: model for oxidant-initiated toxicity. Environmental health perspectives 55: 37-46.

47. Klein C, Westenberger A (2012) Genetics of Parkinson's disease. Cold Spring Harbor perspectives in medicine 2(1): a008888.

48. Roybon L, Christophersen NS, Brundin P, Li JY (2004) Stem cell therapy for Parkinson's disease: where do we stand?. Cell and tissue research 318(1): 261-273.

49. Zhang SC, Li XJ, Johnson MA, Pankratz MT (2007) Human embryonic stem cells for brain repair? Philosophical Transactions of the Royal Society B Biological Sciences 363(1489): 87-99.

50. Ziavra D, Makri G, Giompres P, Taraviras S, Thomaidou D, et al. (2012) Neural stem cells transplanted in a mouse model of Parkinson's disease differentiate to neuronal phenotypes and reduce rotational deficit. CNS Neurological Disorders-Drug Targets 11(7): 829-835.

51. Sander JD, Joung JK (2014) CRISPR-Cas systems for editing, regulating and targeting genomes. Nature biotechnology 32(4): 347-355.
52. Tu Z, Yang W, Yan S, Guo X, Li XJ (2015) CRISPR/Cas9: a powerful genetic engineering tool for establishing large animal models of neurodegenerative diseases. Molecular neurodegeneration 10: 35.

53. Han F, Baremberg D, Gao J, Duan J, Lu X, et al. (2015) Development of stem cell-based therapy for Parkinson's disease. Translational neurodegeneration $4: 16$.

54. Coune PG, Schneider BL, Aebischer P (2012) Parkinson's disease: gene therapies. Cold Spring Harbor perspectives in medicine 2(4): a009431.

55. Cardinale A, Chiesa R, Sierks M (2014) Protein misfolding and neurodegenerative diseases. International journal of cell biology 2014 .

56. Ibáñez CF, Andressoo JO (2017) Biology of GDNF and its receptorsrelevance for disorders of the central nervous system. Neurobiology of disease 97(Pt B): 80-89.

57. Błaszczyk JW (2016) Parkinson's disease and neurodegeneration: GABA-collapse hypothesis. Frontiers in neuroscience 10: 269.

58. Marques 0, Outeiro TF (2012) Alpha-synuclein: from secretion to dysfunction and death. Cell death \& disease 3(7): e350.

59. Oczkowska A, Kozubski W, Lianeri M, Dorszewska J (2013) Mutations in PRKN and SNCA genes important for the progress of Parkinson's disease. Current genomics 14(8): 502-517.

60. Parihar MS, Parihar A, Fujita M, Hashimoto M, Ghafourifar P (2009) Alpha-synuclein overexpression and aggregation exacerbates impairment of mitochondrial functions by augmenting oxidative stress in human neuroblastoma cells. The international journal of biochemistry \& cell biology 41(10): 2015-2024.

61. Ellis CE, Murphy EJ, Mitchell DC, Golovko MY, Scaglia F, et al. (2005) Mitochondrial lipid abnormality and electron transport chain impairment in mice lacking $\alpha$-synuclein. Molecular and cellular biology 25(22): 10190-10201.

62. Klivenyi P, Siwek D, Gardian G, Yang L, Starkov A, et al. (2006) Mice lacking alpha-synuclein are resistant to mitochondrial toxins. Neurobiology of disease 21(3): 541-548.

63. Devi L, Raghavendran V, Prabhu BM, Avadhani NG, Anandatheerthavarada HK (2008) Mitochondrial import and accumulation of $\alpha$-synuclein impair complex I in human dopaminergic neuronal cultures and Parkinson disease brain. Journal of Biological Chemistry 283(14): 9089-9100.

64. Schraen-Maschke S, Sergeant N, Dhaenens CM, Bombois S, Deramecourt V, et al. (2008) Tau as a biomarker of neurodegenerative diseases. Biomark Med 2(4): 363-384.

65. Arima K, Hirai S, Sunohara N, Aoto K, Izumiyama Y, et al. (1999) Cellular co-localization of phosphorylated tau-and NACP/ $\alpha$-synuclein-epitopes in Lewy bodies in sporadic Parkinson's disease and in dementia with Lewy bodies. Brain research 843(1-2): 53-61.

66. Hepp DH, Vergoossen DL, Huisman E, Lemstra AW, Netherlands Brain Bank, et al. (2016) Distribution and load of amyloid- $\beta$ pathology in Parkinson disease and dementia with Lewy bodies. Journal of Neuropathology \& Experimental Neurology 75(10): 936-945.

67. Walker L, McAleese KE, Thomas AJ, Johnson M, Martin-Ruiz C, et al. (2015) Neuropathologically mixed Alzheimer's and Lewy body disease: burden of pathological protein aggregates differs between clinical phenotypes. Acta neuropathologica 129(5): 729-748.

68. Schlossmacher MG, Frosch MP, Gai WP, Medina M, Sharma N, et al. (2002) Parkin localizes to the Lewy bodies of Parkinson disease and dementia with Lewy bodies. The American journal of pathology 160(5): 1655-1667

69. Ariga $H$, Takahashi Niki $K$, Kato I, Maita $H$, Niki T, et al. (2013) Neuroprotective function of DJ-1 in Parkinson's disease. Oxidative medicine and cellular longevity 2013: 683920.

70. Wu HY, Chen SF, Hsieh JY, Chou F, Wang YH, et al. (2015) Structural basis of antizyme-mediated regulation of polyamine homeostasis. 
Proceedings of the National Academy of Sciences 112(36): 1122911234.

71. Dias V, Junn E, Mouradian MM (2013) The role of oxidative stress in Parkinson's disease. Journal of Parkinson's disease 3(4): 461-491.

72. Rodriguez MC, Obeso JA, Olanow CW (1998) Subthalamic nucleusmediated excitotoxicity in Parkinson's disease: a target for neuroprotection. Annals of neurology 44(S1): S175-188.

73. Mark LP, Prost RW, Ulmer JL, Smith MM, Daniels DL, et al. (2001) Pictorial review of glutamate excitotoxicity: fundamental concepts for neuroimaging. American journal of neuroradiology 22(10): 18131824

74. Dong XX, Wang Y, Qin ZH (2009) Molecular mechanisms of excitotoxicity and their relevance to pathogenesis of neurodegenerative diseases. Acta Pharmacologica Sinica 30(4): 379-387.

75. Larsen KE, Sulzer D (2002) Autophagy in neurons: a review. Histology and histopathology 17(3): 897-908.

76. Rubinsztein DC (2006) The roles of intracellular protein-degradation pathways in neurodegeneration. Nature 443(7113): 780-786.

77. Flower TR, Chesnokova LS, Froelich CA, Dixon C, Witt SN (2005) Heat shock prevents alpha-synuclein-induced apoptosis in a yeast model of Parkinson's disease. Journal of molecular biology 351(5): 1081-1100.

78. Tantucci M, Mariucci G, Taha E, Spaccatini C, Tozzi A, et al. (2009) Induction of heat shock protein 70 reduces the alteration of striatal electrical activity caused by mitochondrial impairment. Neuroscience 163(3): 735-740.

79. Parker Jr WD, Parks JK, Swerdlow RH (2008) Complex I deficiency in Parkinson's disease frontal cortex. Brain research 1189: 215-218.

80. Anderson RF, Harris TA (2003) Dopamine and uric acid act as antioxidants in the repair of DNA radicals: implications in Parkinson's disease. Free radical research 37(10): 1131-1136.

81. Lotharius J, Brundin P (2002) Pathogenesis of Parkinson's disease: dopamine, vesicles and $\alpha$-synuclein. Nature Reviews Neuroscience 3(12): 932-942

82. Khoo ML, Tao H, Meedeniya AC, Mackay-Sim A, Ma DD (2011) Transplantation of neuronal-primed human bone marrow mesenchymal stem cells in hemiparkinsonian rodents. PLoS One 6(5): e19025.

83. Blandini F, Cova L, Armentero MT, Zennaro E, Levandis G, et al. (2010) Transplantation of undifferentiated human mesenchymal stem cells protects against 6-hydroxydopamine neurotoxicity in the rat. Cell transplantation 19(2): 203-218.

84. Shukla S, Chaturvedi RK, Seth K, Roy NS, Agrawal AK (2009) Enhanced survival and function of neural stem cells-derived dopaminergic neurons under influence of olfactory ensheathing cells in parkinsonian rats. Journal of neurochemistry 109(2): 436-451.

85. Meyer AK, Maisel M, Hermann A, Stirl K, Storch A (2010) Restorative approaches in Parkinson's Disease: Which cell type wins the race? Journal of the neurological sciences 289(1-2): 93-103.

86. Han F (2012) The applications of the induced pluripotent stem cells in studying the neurodegenerative diseases. Chinese Journal of Cell Biology 34(5): 13.

87. Tsunemoto RK, Eade KT, Blanchard JW, Baldwin KK (2015) Forward engineering neuronal diversity using direct reprogramming. The EMBO journal 34(11): 1445-1455.

88. Altman J, Das GD (1965) Post-natal origin of microneurones in the rat brain. Nature 207(5000): 953-956.

89. Doetsch F, Caille I, Lim DA, García-Verdugo JM, Alvarez-Buylla A (1999) Subventricular zone astrocytes are neural stem cells in the adult mammalian brain. Cell 97(6): 703-716.
90. Taupin P, Gage FH (2002) Adult neurogenesis and neural stem cells of the central nervous system in mammals. Journal of neuroscience research 69(6): 745-749.

91. Nishino H, Hida H, Takei N, Kumazaki M, Nakajima K, et al. (2000) Mesencephalic neural stem (progenitor) cells develop to dopaminergic neurons more strongly in dopamine-depleted striatum than in intact striatum. Experimental neurology 164(1): 209-214.

92. Kim HJ, McMillan E, Han F, Svendsen CN (2009) Regionally specified human neural progenitor cells derived from the mesencephalon and forebrain undergo increased neurogenesis following overexpression of ASCL1. Stem cells 27(2): 390-398.

93. Grimes DA, Han F, Panisset M, Racacho L, Xiao F, et al. (2006) Translated mutation in the Nurr1 gene as a cause for Parkinson's disease. Movement disorders 21(7): 906-909.

94. Shim JW, Park CH, Bae YC, Bae JY, Chung S, et al. (2007) Generation of functional dopamine neurons from neural precursor cells isolated from the subventricular zone and white matter of the adult rat brain using Nurr1 overexpression. Stem Cells 25(5): 1252-1262.

95. Studer L, Tabar V, McKay R (1998) Transplantation of expanded mesencephalic precursors leads to recovery in parkinsonian rats. Nature neuroscience 1(4): 290-295.

96. Monni E, Cusulin C, Cavallaro M, Lindvall O, Kokaia Z (2014) Human fetal striatum-derived neural stem (NS) cells differentiate to mature neurons in vitro and in vivo. Current stem cell research \& therapy 9(4): 338-346.

97. Redmond Jr DE, Vinuela A, Kordower JH, Isacson O (2008) Influence of cell preparation and target location on the behavioral recovery after striatal transplantation of fetal dopaminergic neurons in a primate model of Parkinson's disease. Neurobiology of disease 29(1): 103-116.

98. Lindvall O, Brundin P, Widner H, Rehncrona S, Gustavii B, et al. (1990) Grafts of fetal dopamine neurons survive and improve motor function in Parkinson's disease. Science 247(4942): 574-577.

99. Lindvall O, Sawle G, Widner H, Rothwell JC, Björklund A, et al. (1994) Evidence for long-term survival and function of dopaminergic grafts in progressive Parkinson's disease. Annals of neurology 35(2): 172-180.

100. Freed CR, Greene PE, Breeze RE, Tsai WY, DuMouchel W, et al. (2001) Transplantation of embryonic dopamine neurons for severe Parkinson's disease. New England Journal of Medicine 344(10): 710719.

101. Olanow CW, Goetz CG, Kordower JH, Stoessl AJ, Sossi V, et al. (2003) A double-blind controlled trial of bilateral fetal nigral transplantation in Parkinson's disease. Annals of neurology 54(3): 403-414.

102. Ma Y, Tang C, Chaly T, Greene P, Breeze R, et al. (2010) Dopamine cell implantation in Parkinson's disease: long-term clinical and 18F-FDOPA PET outcomes. Journal of Nuclear Medicine 51(1): 7-15

103. Lindvall 0, Björklund A (2004) Cell therapy in Parkinson's disease. NeuroRx 1(4): 382-393

104. Hagell P, Brundin P (2001) Cell survival and clinical outcome following intrastriatal transplantation in Parkinson disease. Journal of Neuropathology \& Experimental Neurology 60(8): 741-752.

105. Carlsson T, Carta M, Winkler C, Björklund A, Kirik D (2007) Serotonin neuron transplants exacerbate L-DOPA-induced dyskinesias in a rat model of Parkinson's disease. Journal of Neuroscience 27(30): 80118022

106. Politis M, Wu K, Loane C, Quinn NP, Brooks DJ, etal. (2010) Serotonergic neurons mediate dyskinesia side effects in Parkinson's patients with neural transplants. Science translational medicine 2(38): 38ra46.

107. Mendez I, Viñuela A, Astradsson A, Mukhida K, Hallett P, et al. (2008) Dopamine neurons implanted into people with Parkinson's disease survive without pathology for 14 years. Nature medicine 14(5): 507509. 
108. Li JY, Englund E, Holton JL, Soulet D, Hagell P, et al. (2008) Lewy bodies in grafted neurons in subjects with Parkinson's disease suggest hostto-graft disease propagation. Nature medicine 14(5): 501-503.

109. Kordower JH, Chu Y, Hauser RA, Freeman TB, Olanow CW (2008) Lewy body-like pathology in long-term embryonic nigral transplants in Parkinson's disease. Nature medicine 14(5): 504-506.

110. Moore SF, Guzman NV, Mason SL, Williams-Gray CH, Barker RA (2014) Which patients with Parkinson's disease participate in clinical trials? One centre's experiences with a new cell based therapy trial (TRANSEURO). Journal of Parkinson's disease 4(4): 671-676.

111. Evans JR, Mason SL, Barker RA (2012) Current status of clinical trials of neural transplantation in Parkinson's disease. InProgress in brain research 200: 169-198.

112. Han F, Baremberg D, Gao J, Duan J, Lu X, et al. (2015) Development of stem cell-based therapy for Parkinson's disease. Translational neurodegeneration 4(1): 16

113. Thomson JA, Itskovitz-Eldor J, Shapiro SS, Waknitz MA, Swiergiel JJ, et al. (1998) Embryonic stem cell lines derived from human blastocysts. Science 282(5391): 1145-1147.

114. Yan Y, Yang D, Zarnowska ED, Du Z, Werbel B, et al. (2005) Directed differentiation of dopaminergic neuronal subtypes from human embryonic stem cells. Stem cells 23(6): 781-790.

115. Yang D, Zhang ZJ, Oldenburg M, Ayala M, Zhang SC (2008) Human embryonic stem cell-derived dopaminergic neurons reverse functional deficit in parkinsonian rats. Stem cells 26(1): 55-63.

116. Chambers SM, Fasano CA, Papapetrou EP, Tomishima M, Sadelain M, et al. (2009) Highly efficient neural conversion of human ES and iPS cells by dual inhibition of SMAD signaling. Nature biotechnology 27(3): 275-280.

117. Fasano CA, Chambers SM, Lee G, Tomishima MJ, Studer L (2010) Efficient derivation of functional floor plate tissue from human embryonic stem cells. Cell stem cell 6(4): 336-347.

118. Kriks S, Shim JW, Piao J, Ganat YM, Wakeman DR, et al. (2011) Dopamine neurons derived from human ES cells efficiently engraft in animal models of Parkinson's disease. Nature 480(7378): 547-551.

119. Sánchez-Danés A, Consiglio A, Richaud Y, Rodriguez-Piza I, Dehay B, et al. (2011) Efficient generation of A9 midbrain dopaminergic neurons by lentiviral delivery of LMX1A in human embryonic stem cells and induced pluripotent stem cells. Human gene therapy 23(1): 56-69.

120. Schulz TC, Noggle SA, Palmarini GM, Weiler DA, Lyons IG, et al, (2004) Differentiation of human embryonic stem cells to dopaminergic neurons in serum-free suspension culture. Stem cells 22(7): 12181238.

121. Vazin T, Becker KG, Chen J, Spivak CE, Lupica CR, et al. (2009) A novel combination of factors, termed SPIE, which promotes dopaminergic neuron differentiation from human embryonic stem cells. PloS one 4(8): e6606.

122. Swistowski A, Peng J, Han Y, Swistowska AM, Rao MS, et al. (2009) Xeno-free defined conditions for culture of human embryonic stem cells, neural stem cells and dopaminergic neurons derived from them. PloS one 4(7): e6233.

123. Hu S, Zhao MT, Jahanbani F, Shao NY, Lee WH, et al. (2016) Effects of cellular origin on differentiation of human induced pluripotent stem cell-derived endothelial cells. JCI insight 1(8).

124. Colman A (1999) Somatic cell nuclear transfer in mammals: progress and applications. Cloning 1(4): 185-200.

125. Jullien J, Pasque V, Halley-Stott RP, Miyamoto K, Gurdon JB (2011) Mechanisms of nuclear reprogramming by eggs and oocytes: a deterministic process?. Nature reviews Molecular cell biology 12(7): 453-459.
126. French AJ, Adams CA, Anderson LS, Kitchen JR, Hughes MR, et al. (2008) Development of human cloned blastocysts following somatic cell nuclear transfer with adult fibroblasts. Stem cells 26(2): 485-493.

127. Chung Y, Bishop CE, Treff NR, Walker SJ, Sandler VM, et al. (2009) Reprogramming of human somatic cells using human and animal oocytes. Cloning and stem cells 11(2): 213-223.

128. Takahashi K, Yamanaka S (2006) Induction of pluripotent stem cells from mouse embryonic and adult fibroblast cultures by defined factors. Cell 126(4): 663-676.

129. Park IH, Zhao R, West JA, Yabuuchi A, Huo H, et al. (2008) Reprogramming of human somatic cells to pluripotency with defined factors. Nature 451(7175): 141-146.

130. Yu J, Vodyanik MA, Smuga-Otto K, Antosiewicz-Bourget J, Frane JL, et al. (2007) Induced pluripotent stem cell lines derived from human somatic cells. Science 318(5858): 1917-1920.

131. Boyer LA, Lee TI, Cole MF, Johnstone SE, Levine SS, et al. (2005) Core transcriptional regulatory circuitry in human embryonic stem cells. Cell 122(6): 947-956.

132. Huangfu D, Osafune K, Maehr R, Guo W, Eijkelenboom A, et al. (2008) Induction of pluripotent stem cells from primary human fibroblasts with only Oct4 and Sox2. Nature biotechnology 26(11): 1269-1275.

133. Li Y, Zhang Q Yin X, Yang W, Du Y, et al. (2011) Generation of iPSCs from mouse fibroblasts with a single gene, Oct4, and small molecules. Cell research 21(1): 196.

134. Kiskinis E, Eggan K (2010) Progress toward the clinical application of patient-specific pluripotent stem cells. The Journal of clinical investigation 120(1): 51-59.

135. Zeng X, Couture LA (2013) Pluripotent stem cells for Parkinson's disease: progress and challenges. Stem cell research \& therapy 4(2): 25 .

136. Wernig M, Zhao JP, Pruszak J, Hedlund E, Fu D, et al. (2008) Neurons derived from reprogrammed fibroblasts functionally integrate into the fetal brain and improve symptoms of rats with Parkinson's disease. Proceedings of the National Academy of Sciences 105(15): 5856-5861.

137. Han F, Wang W, Chen B, Chen C, Li S, et al. (2015) Human induced pluripotent stem cell-derived neurons improve motor asymmetry in a 6-hydroxydopamine-induced rat model of Parkinson's disease. Cytotherapy 17(5): 665-679.

138. Hargus G, Cooper O, Deleidi M, Levy A, Lee K, et al. (2010) Differentiated Parkinson patient-derived induced pluripotent stem cells grow in the adult rodent brain and reduce motor asymmetry in Parkinsonian rats. Proceedings of the National Academy of Sciences 107(36): 1592115926.

139. Sundberg M, Bogetofte H, Lawson T, Jansson J, Smith G, et al. (2013) Improved Cell Therapy Protocols for Parkinson's Disease Based on Differentiation Efficiency and Safety of hESC-, hiPSC-, and Non-Human Primate iPSC-Derived Dopaminergic Neurons. Stem cells 31(8): 15481562.

140. Ross CA, Akimov SS (2014) Human-induced pluripotent stem cells: potential for neurodegenerative diseases. Human molecular genetics 23(R1): R17-26

141. Soldner F, Hockemeyer D, Beard C, Gao Q, Bell GW, et al. (2009) Parkinson's disease patient-derived induced pluripotent stem cells free of viral reprogramming factors. Cell 136(5): 964-977.

142. Reinhardt P, Schmid B, Burbulla LF, Schöndorf DC, Wagner L, et al. (2013) Genetic correction of a LRRK2 mutation in human iPSCs links parkinsonian neurodegeneration to ERK-dependent changes in gene expression. Cell stem cell 12(3): 354-367.

143. Hallett PJ, Deleidi M, Astradsson A, Smith GA, Cooper O, et al. (2015) Successful function of autologous iPSC-derived dopamine 
neurons following transplantation in a non-human primate model of Parkinson's disease. Cell stem cell 16(3): 269-274.

144. Stadtfeld M, Nagaya M, Utikal J, Weir G, Hochedlinger K (2008) Induced pluripotent stem cells generated without viral integration. Science 322(5903): 945-949.

145. Okita K, Nakagawa M, Hyenjong H, Ichisaka T, Yamanaka S (2008) Generation of mouse induced pluripotent stem cells without viral vectors. Science 322(5903): 949-953.

146. Kaji K, Norrby K, Paca A, Mileikovsky M, Mohseni P, et al. (2009) Virus-free induction of pluripotency and subsequent excision of reprogramming factors. Nature 458(7239): 771-775.

147. Yu J, Hu K, Smuga-Otto K, Tian S, Stewart R, et al. (2009) Human induced pluripotent stem cells free of vector and transgene sequences. Science 324(5928): 797-801.

148. Kim D, Kim CH, Moon JI, Chung YG, Chang MY, et al. (2009) Generation of human induced pluripotent stem cells by direct delivery of reprogramming proteins. Cell stem cell 4(6): 472-476.

149. Nakagawa M, Koyanagi M, Tanabe K, Takahashi K, Ichisaka T, et al. (2008) Generation of induced pluripotent stem cells without Myc from mouse and human fibroblasts. Nature biotechnology 26(1): 101-106.

150. Müller LU, Daley GQ, Williams DA (2009) Upping the ante: Recent Advances in Direct Reprogramming. Molecular Therapy 17(6): 947953.

151. Chen VC, Couture SM, Ye J, Lin Z, Hua G, et al. (2012) Scalable GMP compliant suspension culture system for human ES cells. Stem cell research 8(3): 388-402.

152. O Brien C, Laslett AL (2012) Suspended in culture--human pluripotent cells for scalable technologies. Stem Cell Res 9(2): 167-170.

153. Serra M, Brito C, Correia C, Alves PM (2012) Process engineering of human pluripotent stem cells for clinical application. Trends in biotechnology 30(6): 350-359.

154. Fang R, Liu K, Zhao Y, Li H, Zhu D, et al. (2014) Generation of naive induced pluripotent stem cells from rhesus monkey fibroblasts. Cell stem cell 15(4): 488-496.

155. Caiazzo M, Dell Anno MT, Dvoretskova E, Lazarevic D, Taverna S, et al. (2011) Direct generation of functional dopaminergic neurons from mouse and human fibroblasts. Nature 476(7359): 224-227.

156. Liu X, Li F, Stubblefield EA, Blanchard B, Richards TL, et al. (2012) Direct reprogramming of human fibroblasts into dopaminergic neuron-like cells. Cell research 22(2): 321-332.

157. Kim HS, Kim J, Jo Y, Jeon D, Cho YS (2014) Direct lineage reprogramming of mouse fibroblasts to functional midbrain dopaminergic neuronal progenitors. Stem cell research 12(1): 60-68.
158. Kim J, Su SC, Wang H, Cheng AW, Cassady JP, et al. (2011) Functional integration of dopaminergic neurons directly converted from mouse fibroblasts. Cell stem cell 9(5): 413-419.

159. Wang Q Xu X, Li J, Liu J, Gu H, et al. (2011) Lithium, an anti-psychotic drug, greatly enhances the generation of induced pluripotent stem cells. Cell research 21(10): 1424-1435.

160. Aoi T, Yae K, Nakagawa M, Ichisaka T, Okita K, et al. (2008) Generation of pluripotent stem cells from adult mouse liver and stomach cells. Science 321(5889): 699-702.

161. Aasen T, Raya A, Barrero MJ, Garreta E, Consiglio A, et al. (2008) Efficient and rapid generation of induced pluripotent stem cells from human keratinocytes. Nature biotechnology 26(11): 1276-1284.

162. Kim K, Doi A, Wen B, Ng K, Zhao R, et al. (2010) Epigenetic memory in induced pluripotent stem cells. Nature 467(7313): 285-290.

163. Lister R, Pelizzola M, Kida YS, Hawkins RD, Nery JR, et al. (2011) Hotspots of aberrant epigenomic reprogramming in human induced pluripotent stem cells. Nature 471(7336): 68-73.

164. Hou P, Li Y, Zhang X, Liu C, Guan J, et al. (2013) Pluripotent stem cells induced from mouse somatic cells by small-molecule compounds. Science 341(6146): 651-654

165. Mayshar Y, Ben-David U, Lavon N, Biancotti JC, Yakir B, et al. (2010) Identification and classification of chromosomal aberrations in human induced pluripotent stem cells. Cell stem cell 7(4): 521-531.

166. Gore A, Li Z, Fung HL, Young JE, Agarwal S, et al. (2011) Somatic coding mutations in human induced pluripotent stem cells. Nature 471(7336): 63-67.

167. Laurent LC, Ulitsky I, Slavin I, Tran H, Schork A, et al. (2011) Dynamic changes in the copy number of pluripotency and cell proliferation genes in human ESCs and iPSCs during reprogramming and time in culture. Cell stem cell 8(1): 106-118.

168. Yu Z, Wang T, Xu J, Wang W, Wang G, et al. (2015) Mutations in the glucocerebrosidase gene are responsible for Chinese patients with Parkinson's disease. Journal of human genetics 60(2): 85-90.

169. Soldner F, Laganière J, Cheng AW, Hockemeyer D, Gao Q et al. (2011) Generation of isogenic pluripotent stem cells differing exclusively at two early onset Parkinson point mutations. Cell 146(2): 318-331.

170. Nakagawa M, Taniguchi Y, Senda S, Takizawa N, Ichisaka T, et al. (2014) A novel efficient feeder-free culture system for the derivation of human induced pluripotent stem cells. Scientific reports 4: 3594.

171. Kefalopoulou Z, Politis M, Piccini P , Mencacci N, Bhatia K, et al. (2014) Long-term clinical outcome of fetal cell transplantation for Parkinson disease: Two case reports. JAMA Neurol 71(1): 83-87. 